\title{
Corporate Responsibility for Systemic Occupational Stress Prevention
}

\author{
R. Kasperczyk \\ Victoria University, Australia
}

\begin{abstract}
The purpose of this paper is twofold: to highlight the increased focus on corporate governance responsibility for managing employees' psychological health, and to present an argument for a systemic approach to prevention of occupational stress. The paper commences with a brief description of the problem posed by occupational stress as a threat to organisational effectiveness. It then discusses the types of currently observed organisational responses to this issue and the extent to which they are shaped by beliefs about occupational stress. There are two fundamental approaches to dealing with work stress, one aimed at the individual and the other, at the organisation. The more comprehensive approaches have been increasingly reported to be more effective. The argument for a systemic approach to its prevention is then developed, in line with the risk management framework currently being adopted by Government jurisdictions governing Occupational Health and Safety in Australia and New Zealand. As the stress issue is now couched in health and safety terms, it is a moral and legal duty of the Board to satisfy itself that it is effectively addressed.
\end{abstract}

\section{Keywords}

Occupational stress, job stress, prevention, stress intervention, stress management, risk management, systems approach

\section{Introduction}

Stress in the workplace is recognised as an increasingly significant and global problem in terms of negative economic, health, and social outcomes. The issue of employees' psychological health is relevant to corporate governance to the extent that it concerns organisational effectiveness as well as ethical, moral, legal and financial aspects of responsibility for human resources.

While there is a general agreement amongst the business, practitioners and research community that the experience of stress has adverse consequences for workers and their employing organisations, there is discrepancy in the views regarding its definition, causes, and responsibility for tackling the problem.

These obstacles, however, should not deter decision makers from exploring this important issue, attempting to identify the underlying causal factors under their control and creatively tackling it through evidence-based intervention programs. The organisations that find a way to generate healthy profits without creating risks to mental health of their workforce are likely to benefit from the wellbeing and goodwill of their employees and their enhanced ethical reputation.

Copyright (C) 2010 Victoria University. This document has been published as part of the Journal of Business Systems, Governance and Ethics in both online and print formats. Educational and non-profit institutions are granted a nonexclusive licence to utilise this document in whole or in part for personal or classroom use without fee, provided that correct attribution and citation are made and this copyright statement is reproduced. Any other usage is prohibited without the express permission of the publisher.
Despite the lack of precision in measuring work stress and defining its mechanisms, researchers and practitioners have converged on the notion that it involves an interaction between the individual and the organisation. However complex this interaction may be, its organisational aspects fall within the area of corporate responsibility, similarly to the way in 
which health and safety issues have been accepted in recent years.

While there is little argument about employer's responsibility for ensuring a healthy work system environment in the physical realm, there are some misconceptions about the same obligations in the psychological realm. These stem from the way stress is sometimes conceptualised by decision makers as an individual rather than a corporate problem. The belief that individual employees are responsible for their experience of stress has led to stress prevention strategies addressing individual factors being far more prevalent than those addressing organisational factors. The individual and organisational approaches represent the two fundamental types of methods of managing stress in the workplace. The more comprehensive approaches have been increasingly found to be more effective (LaMontagne et al. 2006; Blewett et al. 2006).

If occupational stress is understood as a transaction between the worker and the work environment (Cox \& Griffiths 1995; Israel 1996), then it has significant implications for corporate governance in the areas of organisational effectiveness, employee health, employee performance and risk management. This concept of work stress has led to recent developments in Occupational Health and Safety (OHS) legislation reinforcing employers' responsibility for providing a work environment that is free of risk to employees' psychological health. As OHS legislation and various regulations define criminal law duties for organisational entities and natural persons in charge of them, it is important to ensure that psychological health is managed with the same rigour and determined focus as physical safety, and to minimise exposure of risk for those responsible for corporate governance.

\section{The costly problem of occupational stress}

As organisations face pressures to maximise productivity and minimise costs due to increased global competition and rapid advances in technology, the resulting outcomes for their employees are greater work intensity and lesser job security (European Agency for Safety and Health 2007). These global factors are believed to have produced a more stressful work environment generally, however, there are many other local management factors such as unsupportive and laissez faire leadership styles, interpersonal conflict, and poor job design, that have been linked to high stress outcomes (Caulfield et al. 2004; Dollard \& Knott 2004; D’Aleo et al. 2007).

The extent of the work stress problem can be readily measured in terms of direct costs of workers' compensation claims relating to psychological injury. In Australia, workers are entitled to claim for work related injury including mental health, popularly referred to as "stress claims". The number of claims in the "mental stress" category has grown rapidly in the last decade (from 4440 claims in 199798 to 8665 in 2004-05, representing 95\% growth) while the annual number of overall workers' compensation claims decreased by $13 \%$, in the comparable period. Despite recent initiatives in various compensation jurisdictions to reduce access to such claims, their costs as a proportion of overall compensation expenditure keep increasing. (Australian Safety and Compensation Council 2008).

The direct cost of stress in Australia is estimated to be in excess of $\$ 100 \mathrm{M}$ out of an $\$ 8 \mathrm{~B}$ expended on work injury compensation (Australian Safety and Compensation Council 2009). Serious claims involving mental stress have consistently the longest median time lost from work (10 weeks, compared to 3.8 weeks for all serious claims) and the largest median cost (\$12,700 per claim), (Australian Safety and Compensation Council 2008).

Significant costs and incidence of stress have also been reported worldwide. In the UK, the leading employers' association, Confederation of British Industry ranks stress as the second highest cause of absenteeism estimated to cost British industry well in excess of $£ 10 \mathrm{bn}$. Surveys of workers in Europe, UK and US have consistently found about 30\% reporting that they find their work stressful. (Giga et al. 2003b; Murphy \& Sauter 2003; Jordan et al. 2003).

The costs to the economy related to workplace stress are far greater than those directly attributed to workers' compensation. Indirect social costs of work stress have been linked to poor physical health outcomes mental health problems, mental illness, and unhealthy behaviours [1]. Additional costs to organisations include unplanned absences, employee turnover, increased industrial accidents, lower 
morale and lower productivity (De Bruin \& Taylor 2005; Caulfield et al. 2004; Senol-Durak, Durak \& Gençöz 2006)[1].

\section{Understanding work and stress}

\section{Organisational factors linked to stress}

Various definitions of stress gave rise to many theoretical frameworks over the years. A growing convergence of the stress definition has been on a harmful psychological and/or physiological response of the individual that has both emotional and cognitive components and that is a product of an imbalance between appraisals of environmental demands and individual coping resources (Cox \& Mackay 1981; Israel 1996).

The features of the work environment linked to stress responses have also been increasingly agreed upon, particularly following the UK and European research leadership in this area. A series of studies led by the UK Health and Safety Executive (HSE) has narrowed the number of environmental factors which have been linked to harmful stress responses. The HSE taxonomy (Cox \& Griffiths 1995) which later gave rise to management standards aimed at creating a healthy organisational environment have been narrowed down to the following seven factors (Mackay et al. 2004):

- Demands (including workload and work patterns)

- Control (how much say the person has in the way they do their work)

- Support (including management encouragement, supportive leadership and resources)

- Relationships at work (including interpersonal interactions and the processes of dealing with conflict)

- Role (clarity of the worker's understanding their role and the degree of role conflict)

- Change (how it is managed and communicated within the organisation)

- Culture (the way organisations demonstrate their commitment to fairness and openness).

The HSE approach has been underpinned by an Occupational Health and Safety paradigm which has led to the development of intervention strategies within the risk management framework, adopted by Governmental OHS jurisdictions within Australia and New Zealand. This paradigm is a useful reminder of health-promoting aspects of work. While stress research focuses on the negative aspects of work that potentially cause harm, the same factors, when managed well, produce positive psychological and social outcomes.

All of these factors are within the control of executive management for which they need to be accountable to their Boards or others responsible for corporate governance because of their impact on resources, employees' health and therefore corporate risk and organisational effectiveness.

\section{Causal links between work environment and stress}

Evidence of causal links between the work environment and psychological harm experienced by workers is found in two lines of evidence. First of these is from empirical studies of real work conditions, and second from epidemiological studies of biological pathways of how injury is sustained (Mackay et al. 2004).

There is now solid evidence of biological mechanisms that link psychosocial hazards in the workplace to poor health or disease such as cardio-vascular, coronary, blood pressure levels and poor mental health outcomes. These include physical changes such as immune system responses, neuro-endocrine changes, blood coagulation disturbances, to name a few and psychological mechanisms such as anxiety, hyper-vigilance and risk taking (Bosma et al. 1997; Yusuf et al. 2004).

Mental and psychological ill health, including: anxiety, depression and emotional exhaustion have also been linked to specific psycho-social work factors such as lack of job control, work overload, and unclear work roles. Evidence is also building on the relationship between the work environment and health behaviours such as smoking, lack of activity, poor diet and alcohol consumption. These in turn, form an indirect link between work and ill physical health, (LaMontagne et al. 2006). 


\section{Risk Management nomenclature}

Couching the discussion of stress in risk management terms adds clarity and provides a solid basis for its prevention. If stress is agreed to be a negative and harmful response, what previously might have been referred to as stressors or stress factors can be described as hazards within this framework.

A hazard is defined as an event, a situation or an aspect of work which has the potential to cause harm (Cox et al. 2000). The concept of risk provides an estimate of such a potential of harm when the frequency of exposure to the hazard, and the probability and severity of its negative consequences are considered. Psychological injury or harm become far more precise terms than "stress" which will continue imply a negative response within an individual, a precursor to or a warning signal of potential harm.

The risk management approach to understanding and preventing stress has gained an increasing acceptance in UK, Europe, New Zealand Australian Health and Safety jurisdictions (refer to Table 1). In this paradigm, the mechanism of injury is treated in the same way as in physical injuries, recognising that the injury occurs as a result of the interaction between the individual and the environment. For example, the worker's exposure to a slippery floor hazard may lead to their injury only if they interact with it by slipping. Increased exposure to a physical hazard and certain personal characteristics (such as poor sensory-motor co-ordination) will cause increased risk in the same way that some individuals will be at greater risk of psychological harm due to their transactions with those aspects of work known to act as psycho-social hazards.

As shown in Table 1, all the Australian and New Zealand jurisdictions regulate risk management approaches to be adopted as a way of ensuring a healthy work environment and all of them imply that mental health issues are encompassed by the same regulations as the physical. Some, however, do so explicitly, either through a general definitional inclusion (e.g. Victoria) general statements about psychological hazards (e.g. NSW, NZ) or references to specific psycho-social hazards. The most commonly occurring hazards are singled out in OHS legislation are: bullying, occupational violence, fatigue and change (e.g. SA). 


\begin{tabular}{|c|c|c|c|c|}
\hline 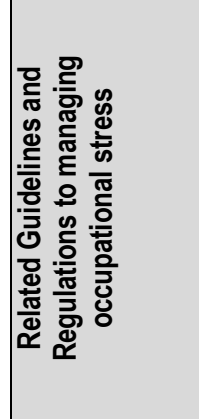 & 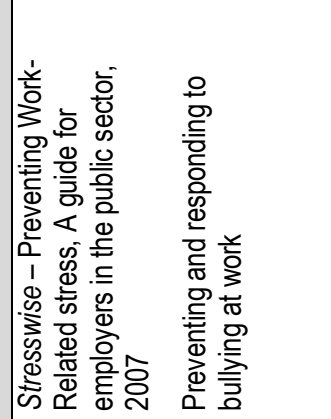 & 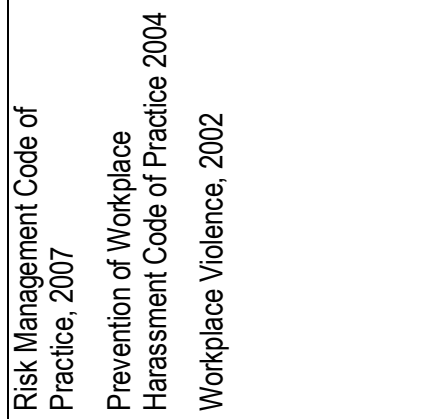 & 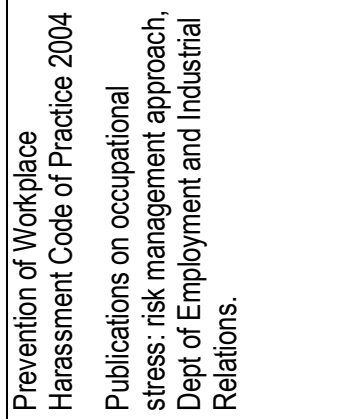 & 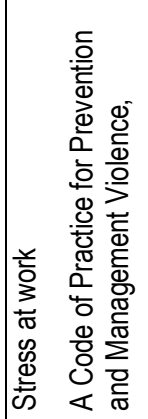 \\
\hline 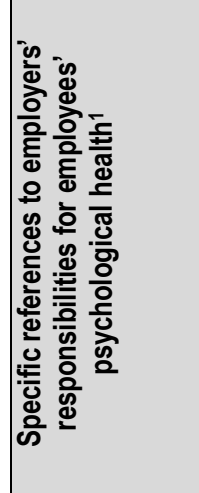 & 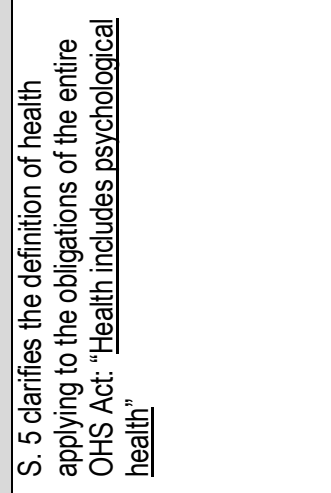 & 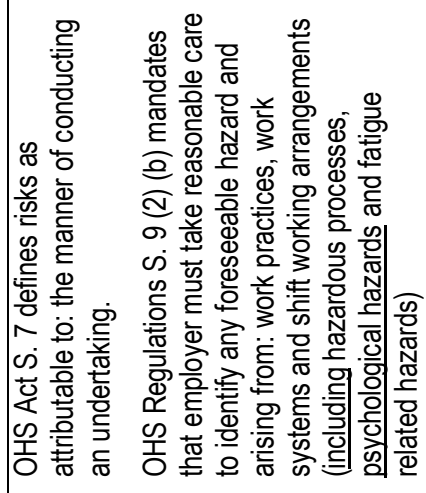 & 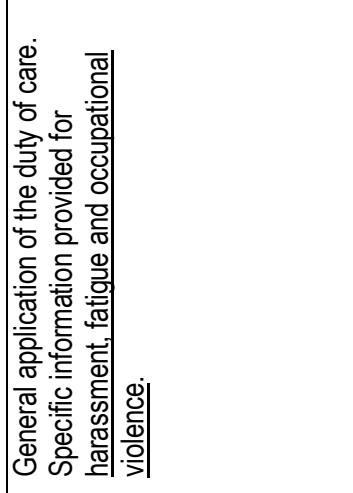 & 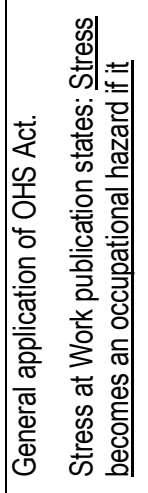 \\
\hline 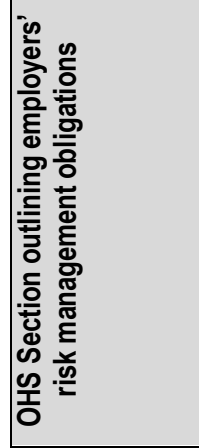 & 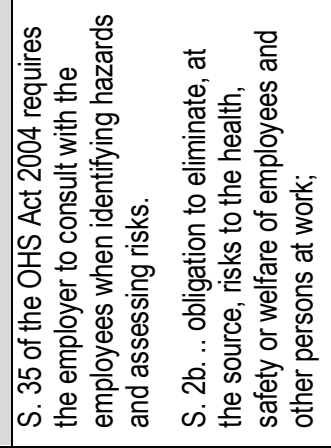 & 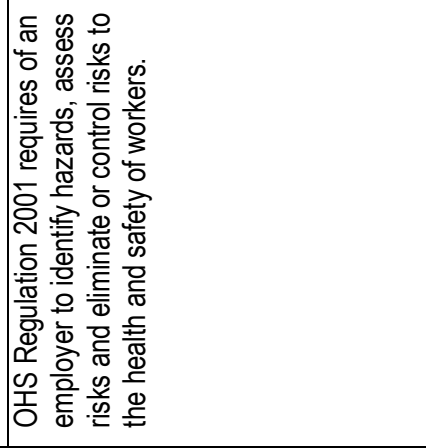 & 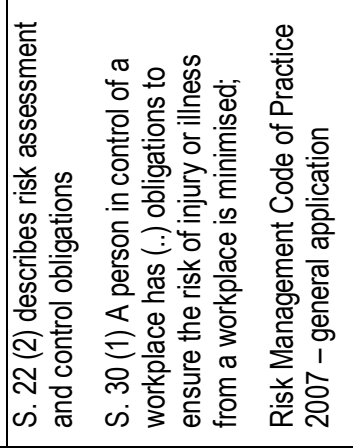 & 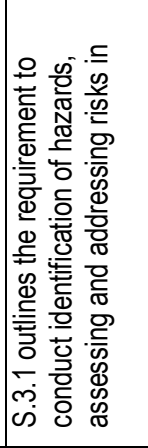 \\
\hline 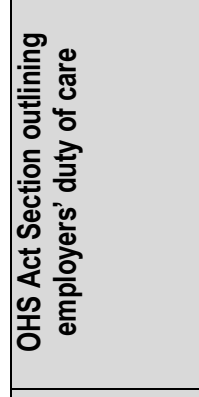 & 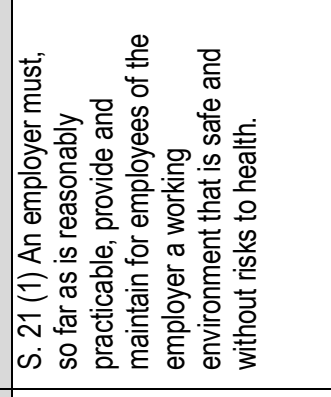 & 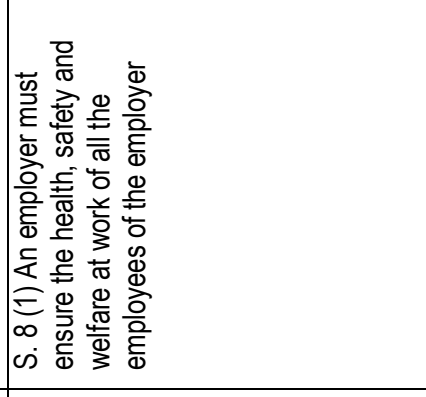 & 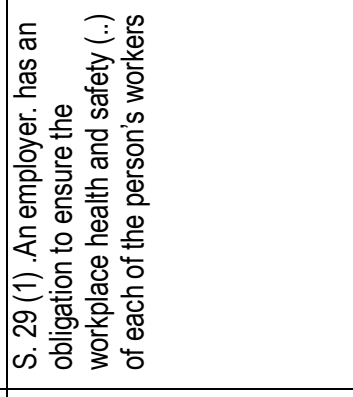 & 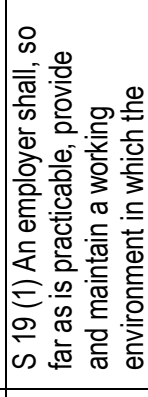 \\
\hline 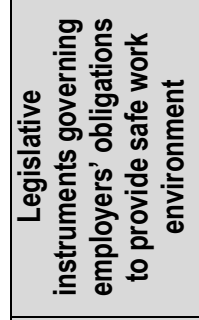 & 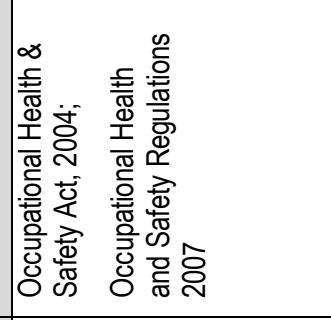 & 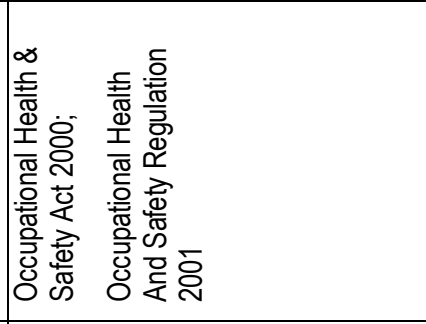 & 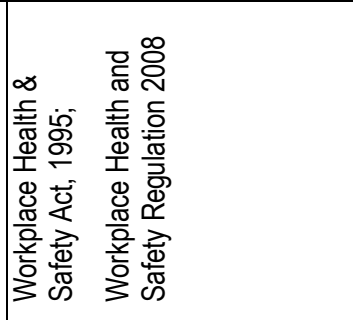 & 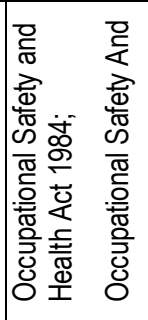 \\
\hline 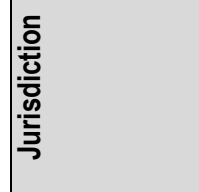 & $\frac{\pi}{\frac{\pi}{0}}$ & 雍 & 믕 & 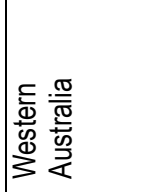 \\
\hline
\end{tabular}




\begin{tabular}{|c|c|c|c|c|c|c|c|}
\hline 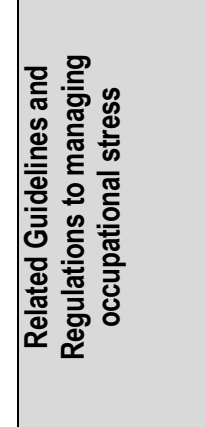 & 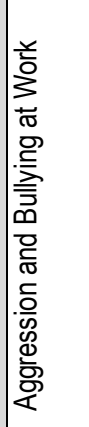 & & 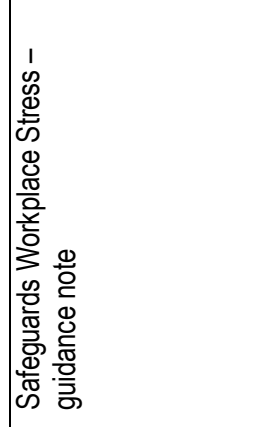 & & 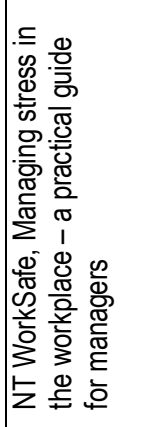 & 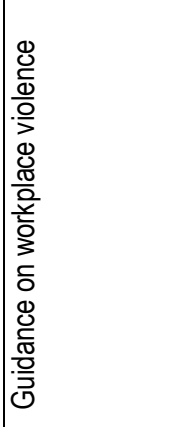 & 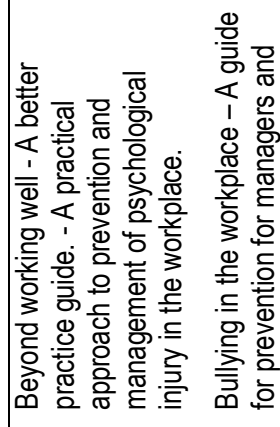 \\
\hline 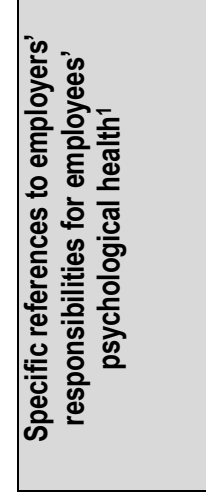 & 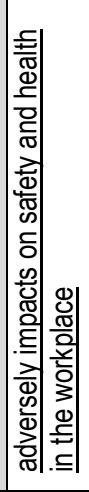 & 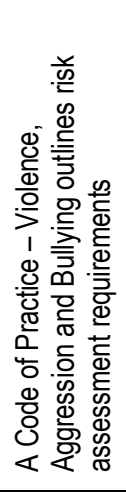 & 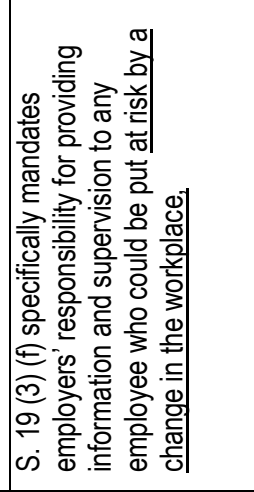 & 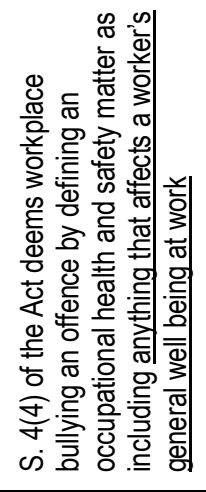 & 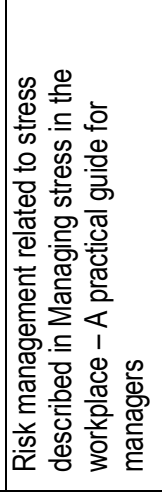 & 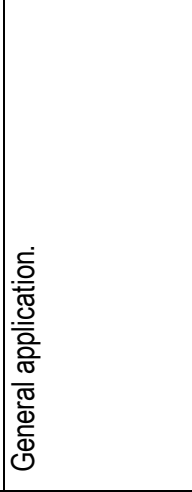 & 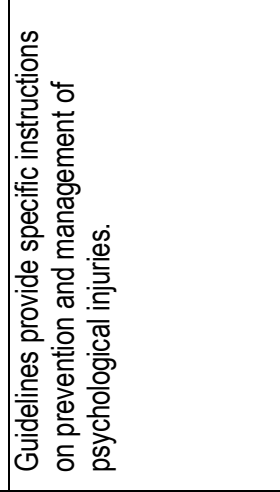 \\
\hline 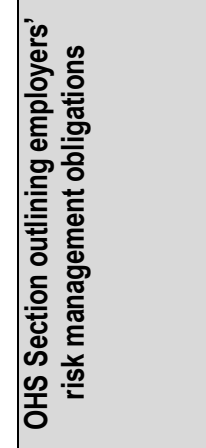 & 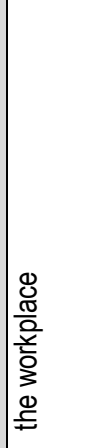 & & 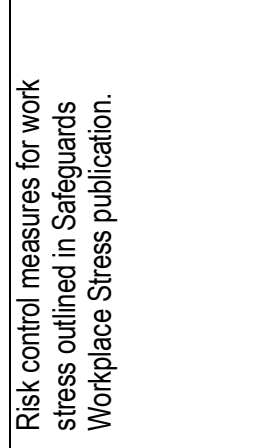 & & 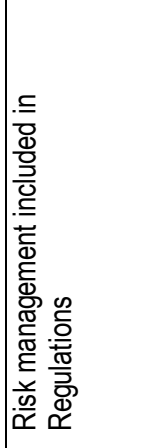 & 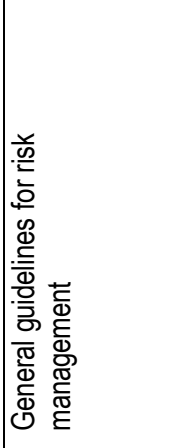 & 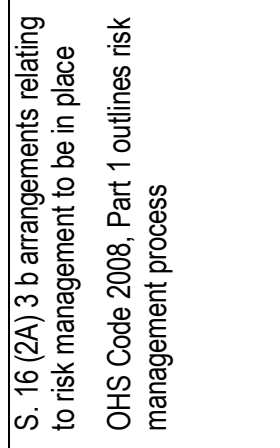 \\
\hline 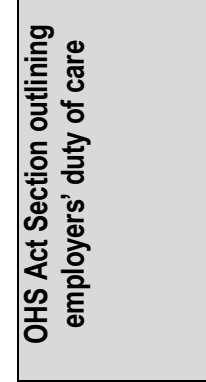 & 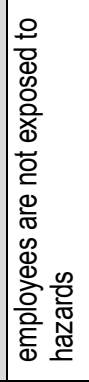 & & 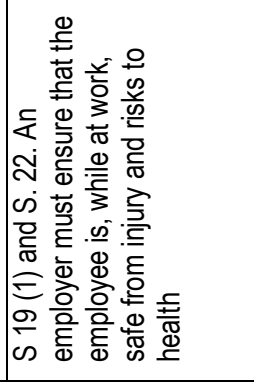 & & 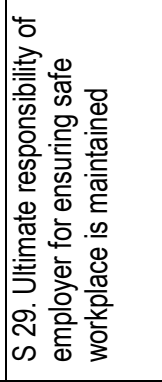 & 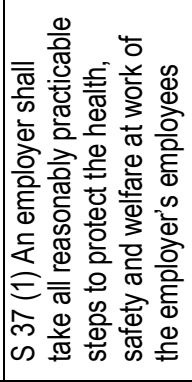 & 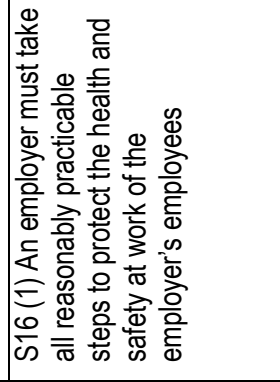 \\
\hline 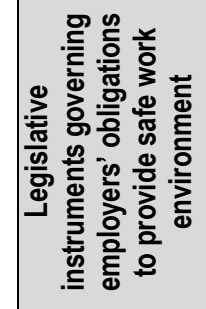 & 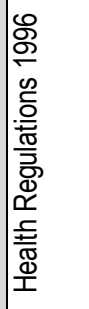 & & 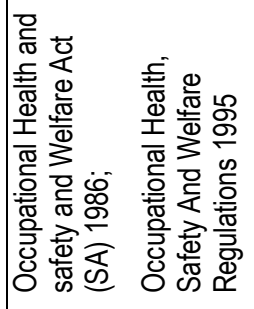 & & 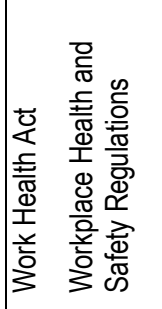 & 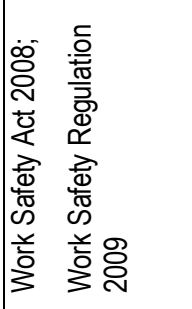 & 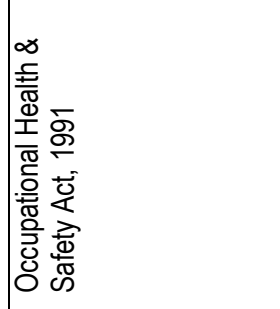 \\
\hline 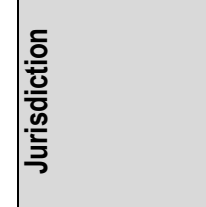 & & & 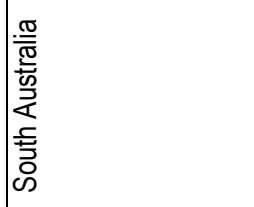 & & 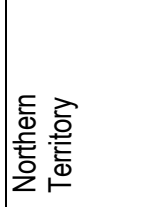 & & 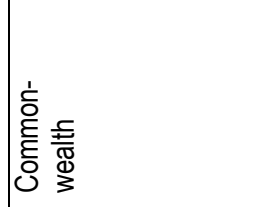 \\
\hline
\end{tabular}




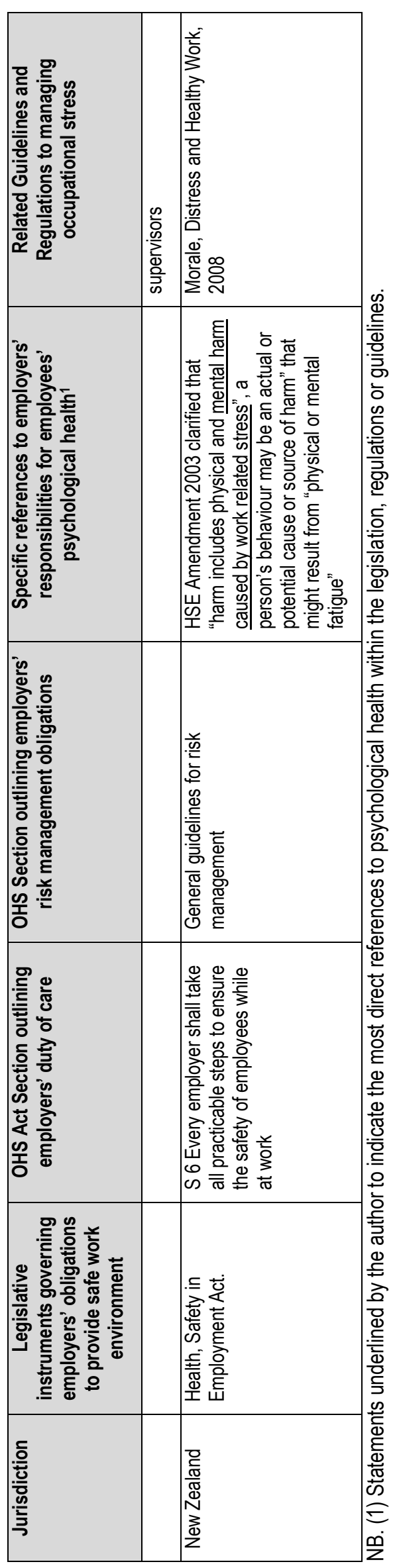




\section{Corporate Responsibility}

The risk management approach to understanding stress assumes a causal link between hazards and potential harm, without the need to focus on the individual responses. As such, organisations need to manage this issue in a similar manner to any other risk arising from their business activities. There is a distinct lack of evidence, however, that this area of corporate responsibility is assumed with the same rigour as other risks, for example, physical safety, financial or technological.

It is proposed that underlying this lack of activity in the area of organisation-level stress prevention is the belief, amongst organisational decision makers, that main cause of "stress" should be attributed to the individual, for example their coping resources or their personality profile. Such belief which is a necessary precursor to action, according to the Theory of Planned Behaviour, forms a barrier to any meaningful change required at the organisational level to control the hazards and therefore prevent stress.

Employers tend to hold the view that causes are found within the individual, whereas unions are more likely to espouse the view that work environments cause stress (Sanders 2001; LaMontagne et al. 2006; Redfern, Rees \& Rowlands 2008). Different beliefs underlying the understanding of stress lead to ineffective communication amongst the key organisational stakeholders and slow progress in improving the effectiveness of its prevention.

Some researchers are more direct in placing the responsibility for failing to prevent work stress at its sources with the managers. Giga, Cooper \& Faragher (2003a, p. 282) proposed as one of the reasons for the individual focused approach as Senior management failing to take responsibility - blaming employee personality and lifestyle rather than employment factors".

The question of responsibility for causing harmful effects is directly related to sense of responsibility for their prevention and management. At the moment, it appears that there is still no agreement reached on the question: "who is responsible for minimising stress in the workplace?" (Sanders 2001).

There are examples emerging of some Boards taking the lead on this responsibility. The UK's HSE has nominated, for example, five companies as "beacons of excellence" demonstrating top management commitment to preventing occupational stress (Jordan et al. 2003). One of the named companies was Rolls-Royce whose Health Safety and Environment Committee reports directly to the Board and is chaired by the Chief Operating Officer. One of its initiatives was a comprehensive stress prevention program, including managers' tools and education (Rolls-Royce Annual Report 2006). It is not a coincidence that the company's Code of Ethics explicitly refers to its commitment to making proper provisions for the health, safety and wellbeing of its employees (Rolls-Royce Global Code of Business Ethics 2009).

\section{Approaches to stress prevention}

A stress intervention program has been defined as "any activity or program initiated by an organisation that focuses on reducing the presence of work-related stressors or assisting individuals to minimise the negative outcomes of exposure to these stressors" (Ivancevich et al. 1990).

Organisations at times react to the need to reduce stress in their workplaces. Often this need is recognised through poor people-related outcomes, such as unplanned absences or high cost of stressrelated workers' compensation claims. However, there appears to be a lack of congruence between the insight about the stress processes gained from research and stress interventions within organisations. In general, the budgets allocated to reducing and combating workplace stress do not appear to be commensurate with the level of its indirect and direct costs, about which there is general agreement (Cooper et al. 2001; Giga et al. 2003b).

\section{Categories of interventions}

Stress interventions have been categorised along two broad dimensions: (1) the degree of prevention, i.e. primary, secondary and tertiary, and (2) the level of organisational involvement, i.e. organisationwide, team-based, individual, and a combination of these (Sutherland \& Cooper 2000). 
Primary prevention refers to those strategies that aim to prevent the occurrence of stress, secondary approaches refer to those that ameliorate the effects of stress once its experience has been noticed and reported and tertiary interventions deal with the enduring health outcomes of stress through rehabilitation and return to work processes.

Examples of primary prevention, or organisational level interventions, are job and/or process redesign, leadership development programs, cultural change etc. Secondary prevention at individual level interventions includes Employee Assistance Programs (EAPs), Cognitive-Behavioural therapeutic or stress management training approaches. Examples of tertiary intervention programs are rehabilitation programs assisting those who have suffered psychological injury due to stress to return to work.

\section{Individual approaches}

Interventions within the individual category include the following programs: relaxation training with and without biofeedback, meditation, cognitive-behavioural therapy, physical exercise, time management training, Employee Assistance Programs, other health promotional education (Giga et al. 2003b). Some approaches include a combination of these programs, however, all of these are based on the assumption that altering the individual's perceptual, information processing, cognitive and behavioural responses are sufficient in order to reduce the probability of harmful stress effect. They also fundamentally ascribe the responsibility for managing stress to the individual.

\section{Organisational approaches}

Organisational level interventions tend to be proactive in nature and thus belonging in the primary prevention category of stress interventions. There are numerous examples of organisational-level interventions as they can include any program designed to develop and improve organisational health. All of these can have preventive effects on employees' health.

Giga, Cooper \& Faragher (2003a) have identified the following programs reported in various studies as organisational stress intervention: Selection and placement, training and development programs, improvements in physical environments, communication improvements, and job design/ restructure, and combinations. There are also combinations of these approaches.

Some of these organisational approaches listed above are immediately recognised as standard management programs adopted at various cycles of organisational life to effect change or improvement in performance. The extent to which these can be classified as stress intervention programs depends on the purpose for which they are enacted.

\section{Multi-modal approaches}

Stress intervention approaches combining individual and/or team with an organisational strategy are referred to as multi-modal. Examples of such programs at both individual and organisational levels are the creation of peer support groups, improving worker participation, Cognitive Behavioural Therapy (CBT) based training and relaxation.

The most common approach observed in organisations is found in the secondary - individual category. These types of intervention programs aim at the individual altering his or her perceptions of the work environment and learning resilience and coping skills to reduce the negative impact of potential stressors (Richardson \& Rothstein 2008).

\section{Systems approach to stress intervention}

An organisational intervention that has become known as comprehensive or a systems approach is noted by a number of components including context-specific identification of those aspects of work that pose hazard to employees' psychological health. One formal approach to such an assessment is the risk management methodology with includes hazard identification, assessment of risk and planning (Cox \& Griffiths 1995), as a component of the organisation's Occupational Healthy and Safety system. 
The Vichealth study classified stress intervention evaluation studies as having a "high" systems approach if they were focused on primary prevention directed at the organisation and environment, if they were integrated with either secondary and/or tertiary interventions, and if there was a stakeholder participation in the conduct of needs or risk assessment (LaMontagne et al. 2006).

The following general hallmarks are typical of a stress intervention program that can be classified as being systemic (Jordan et al. 2003):

1. Risk assessment methodology

2. Top management commitment

3. A participative approach

4. A formal stress prevention strategy

5. Stress prevention activity.

Researchers consider that practice in the above five areas to be essential to the development of a comprehensive stress prevention program and a culture that supports healthy workplace practices (Jordan et al. 2003).

An important point of differentiation of a systemic approach is the emphasis of an accurate assessment of specific and context-specific risks. By focusing on the work aspects to which the employees are exposed and which they report are most associated with negative effects employers, the prevention programs can be intelligently designed and evaluated [2]. A prevention program that adopts the international risk management standards has built-in components of a systems approach.

\section{Evaluation of Effectiveness of Interventions}

Definitional and theoretical differences in approaching stress by various researchers have led to different intervention approaches. There have also been varying approaches to studying the effectiveness of those interventions. Some studies use pre- and post-intervention individual measures of stress responses, using either physiological, psychometric tests or qualitative self-reports. Others utilise organisational measures, typically involving perceptions of the participants and rarely quantitative organisational outcomes.

A number of meta-studies have recently emerged providing a comprehensive analysis of the known effectiveness of stress interventions both internationally (Kompier et al. 2000; van der Klink et al. 2001; Jordan et al. 2003; Giga et al. 2003b, Richardson \& Rothstein, 2008) and locally in Australia (Caulfield et al. 2004; LaMontagne et al. 2006, Blewett et al. 2006). These have limited their selection of source studies on the basis of rigorous evaluation methodology.

The meta-studies addressing the effectiveness of stress interventions published in the last twenty years were identified through the search utilising EBSCO host search engine (incorporating: Business Source Complete, PsycARTICLES, PsycINFO, Medline, and Blackwell Encyclopedia of Management Library). The following groups of terms were used for this search: "Stress" and "work" and Prevention or Intervention" and "Meta-Analysis", "Analysis" or "Evaluation". Search was limited to peer reviewed articles and to the period of publication between 1979 and 2009.

The following criteria were used to select the meta-analysis studies of stress prevention for analysis:

- International and Australian studies were included;

- The source studies' methodological rigour was assessed by the reviewers and studies were rejected if they did not meet a certain standard;

- Studies were published either in a peer-reviewed journal or were commissioned by a government institution.

In addition, research review articles referenced in all of them were included. Other reviews were obtained through searching OHS related institutional Australian websites such as State Government Departments responsible for regulating OHS e.g. WorkSafe and Safe Work Australia. The results of this meta-analysis are shown in Table 2. 


\begin{tabular}{|c|c|c|c|c|c|}
\hline 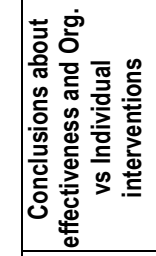 & 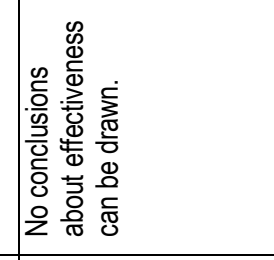 & 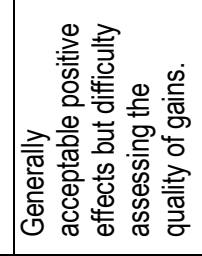 & 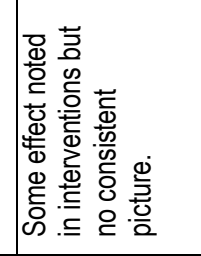 & 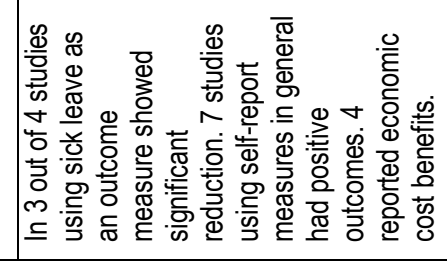 & 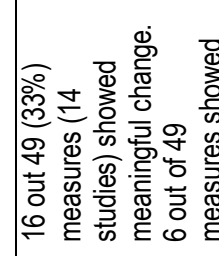 \\
\hline 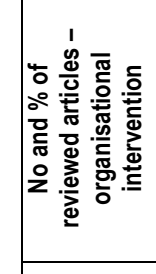 & 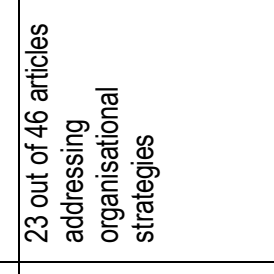 & 产 & 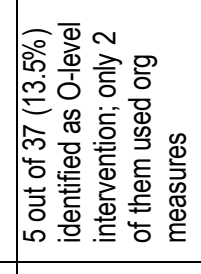 & 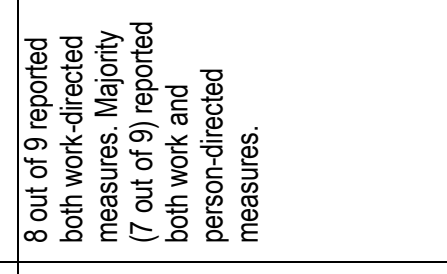 & 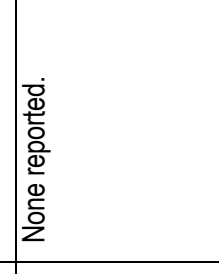 \\
\hline 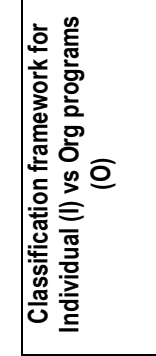 & 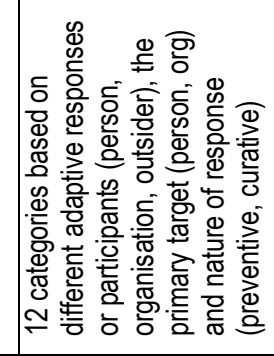 & 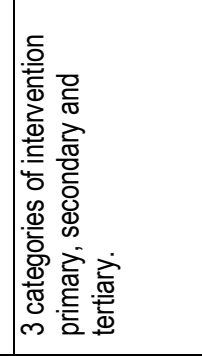 & 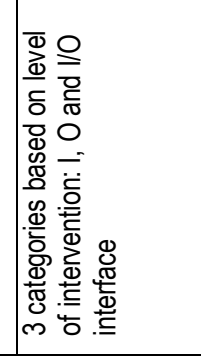 & 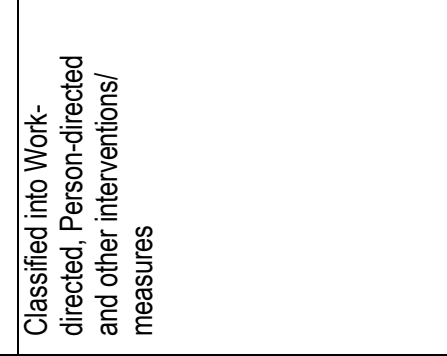 & 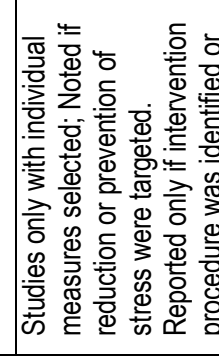 \\
\hline 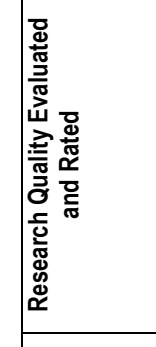 & 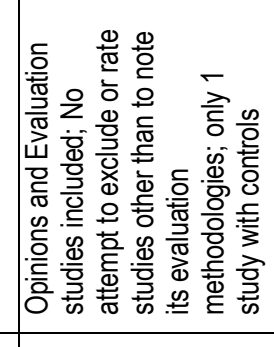 & 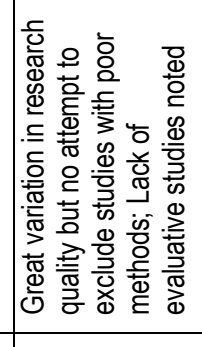 & 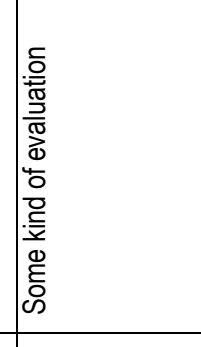 & 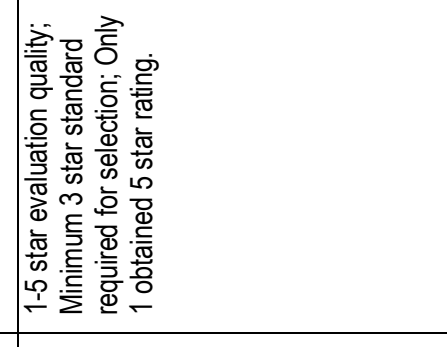 & 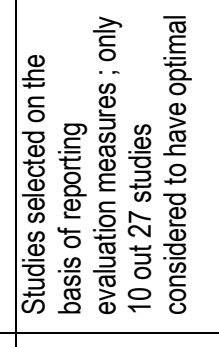 \\
\hline 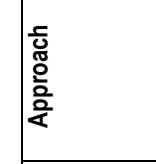 & 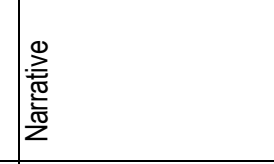 & 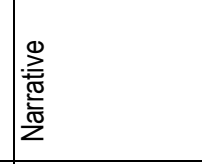 & 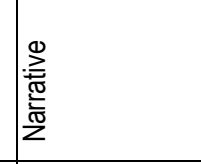 & 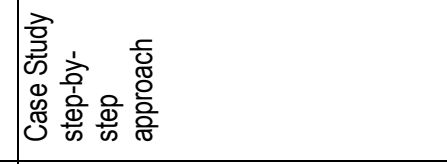 & 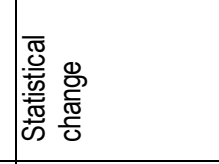 \\
\hline 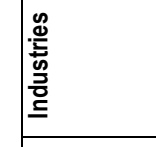 & 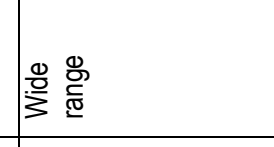 & 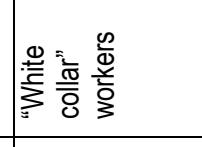 & 造 总 & 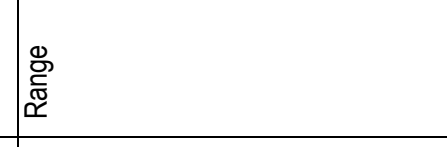 & 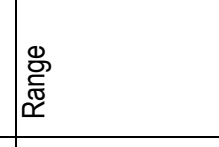 \\
\hline 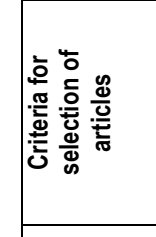 & 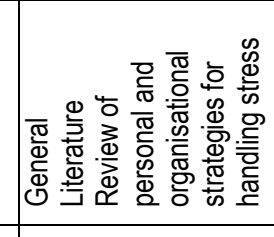 & 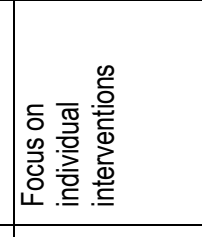 & 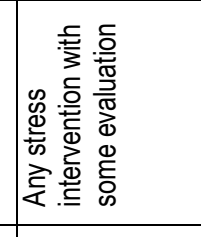 & 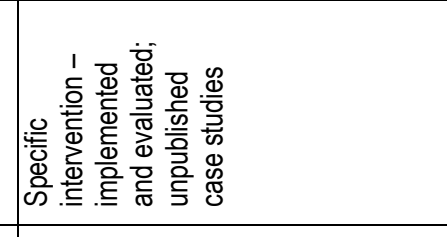 & 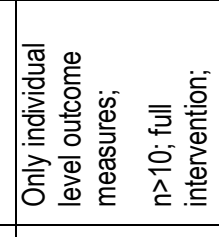 \\
\hline 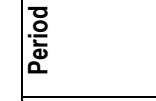 & 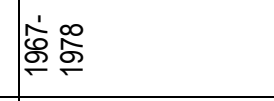 & 念営 & 寠す & 흔 & 兽 \\
\hline 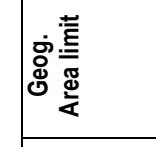 & \begin{tabular}{|l} 
量 \\
\end{tabular} & \begin{tabular}{|l}
$\underline{\underline{\underline{E}}}$ \\
$\underline{\underline{5}}$
\end{tabular} & 豆 & \begin{tabular}{|l} 
总 \\
䇋
\end{tabular} & E्E \\
\hline 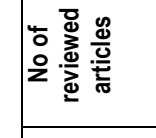 & iq & $\dddot{m}$ & है & o & $\bar{N}$ \\
\hline 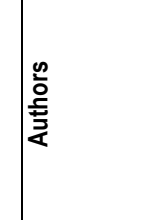 & 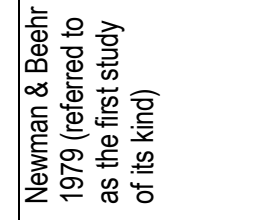 & 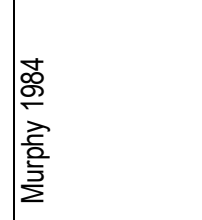 & 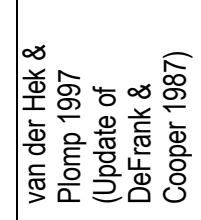 & 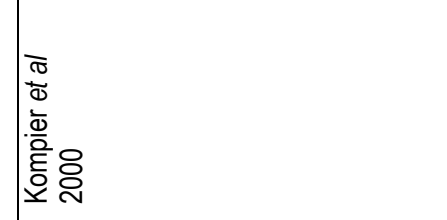 & 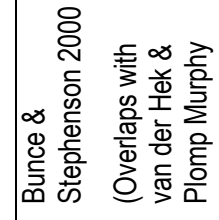 \\
\hline
\end{tabular}




\begin{tabular}{|c|c|c|c|c|}
\hline 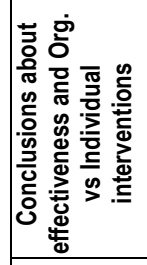 & 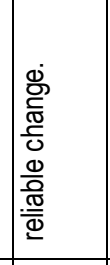 & 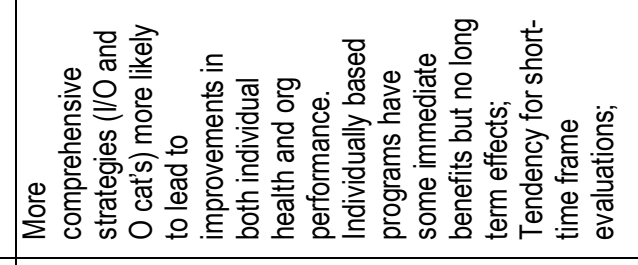 & 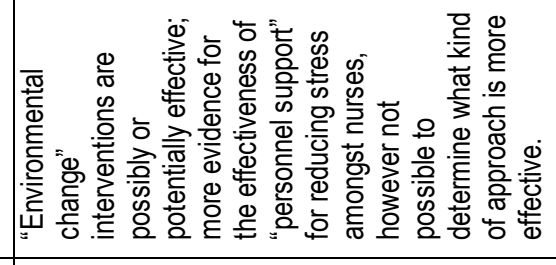 & 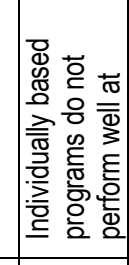 \\
\hline 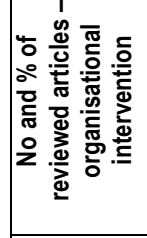 & & 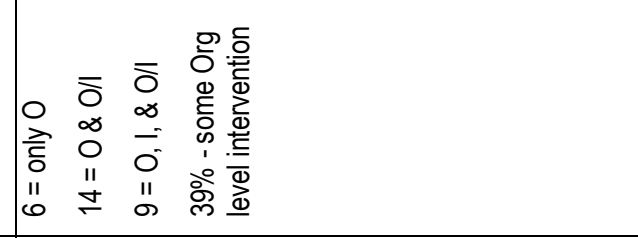 & 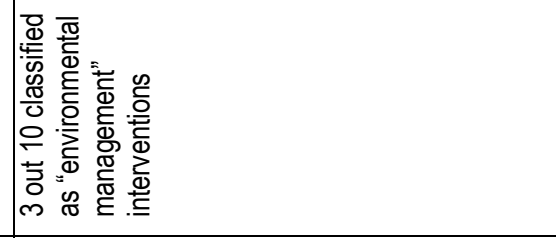 & 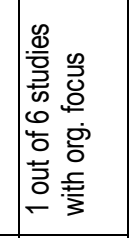 \\
\hline 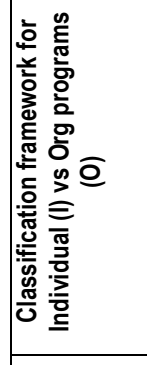 & 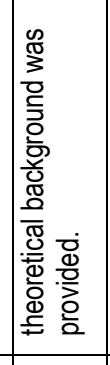 & 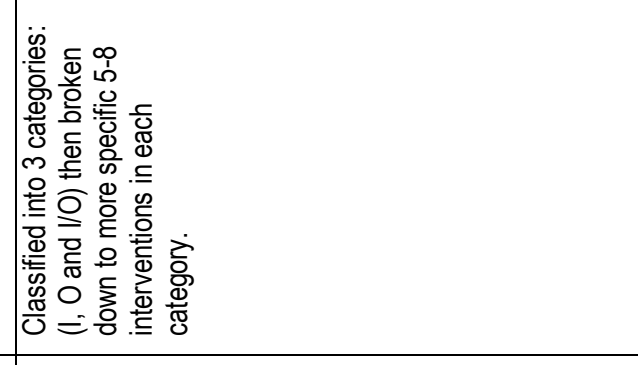 & 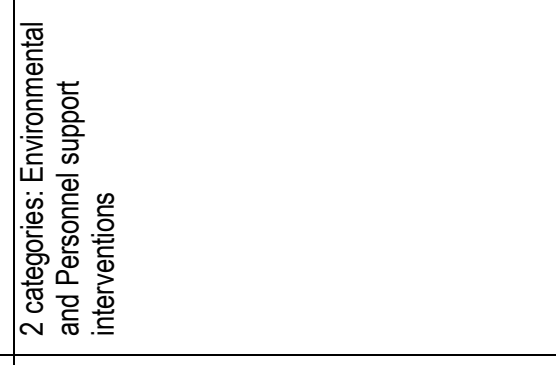 & 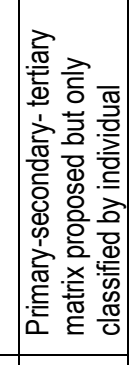 \\
\hline 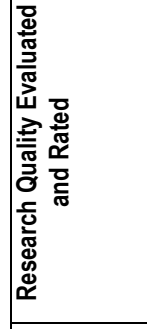 & 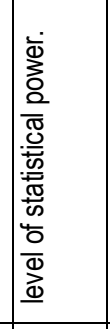 & 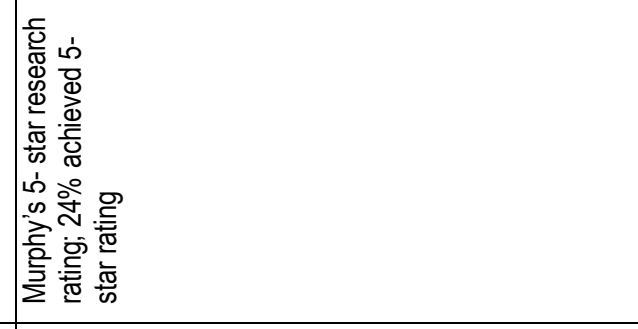 & 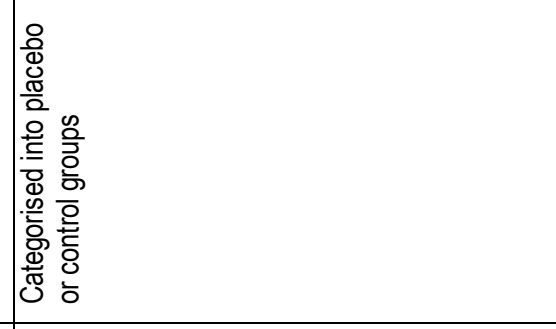 & 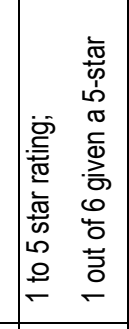 \\
\hline $\begin{array}{l}\frac{1}{\mathrm{a}} \\
\frac{\mathrm{g}}{2} \\
\frac{3}{4}\end{array}$ & & 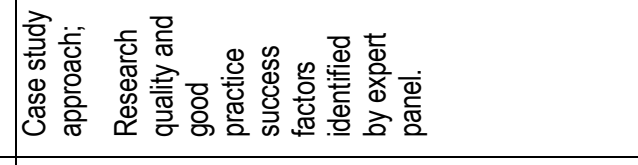 & 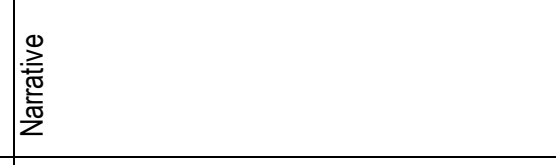 & 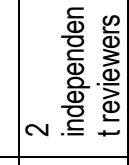 \\
\hline 离 & & 兽 & 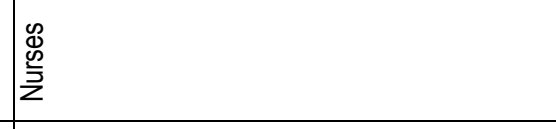 & 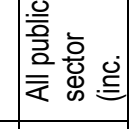 \\
\hline 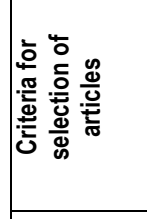 & 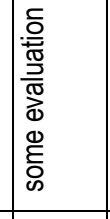 & 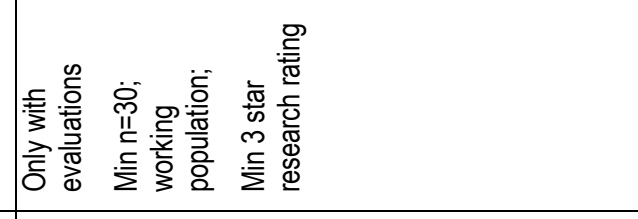 & 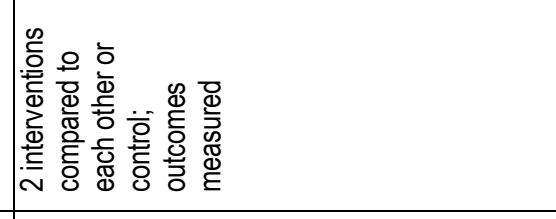 & 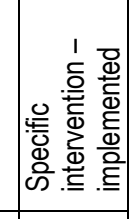 \\
\hline 总 & & 离高 & ஓ̊̀ & 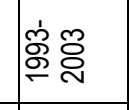 \\
\hline 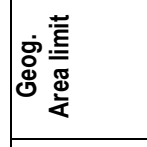 & & $\underline{\underline{\underline{ }}}$ & $\underline{\underline{\underline{E}}}$ & 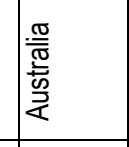 \\
\hline 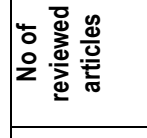 & & I & $\circ$ & 0 \\
\hline 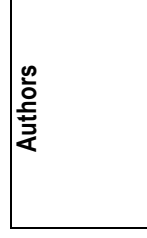 & 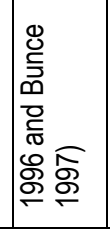 & 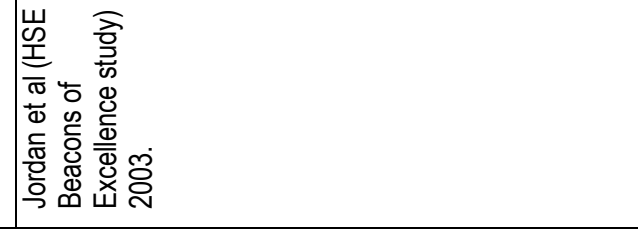 & 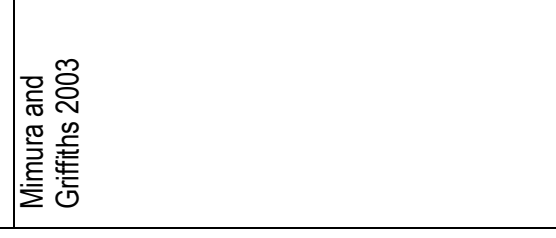 & 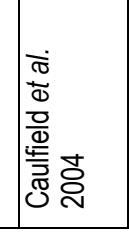 \\
\hline
\end{tabular}




\begin{tabular}{|c|c|c|c|c|}
\hline 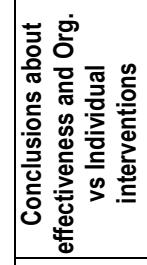 & 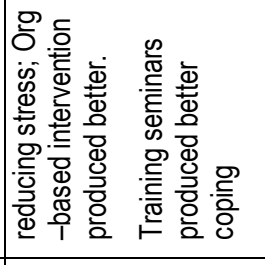 & 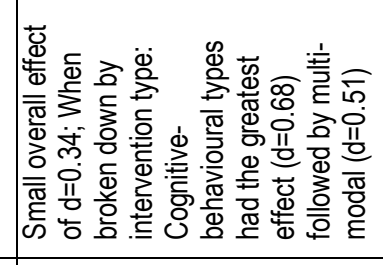 & 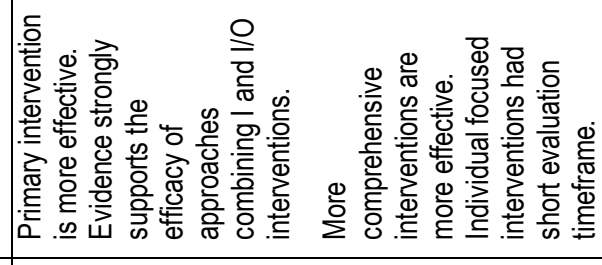 & 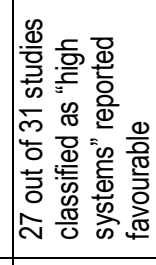 \\
\hline 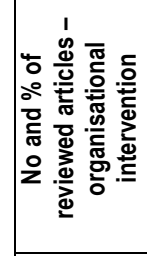 & & 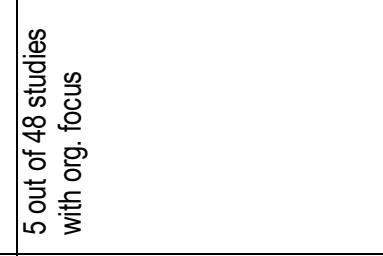 & 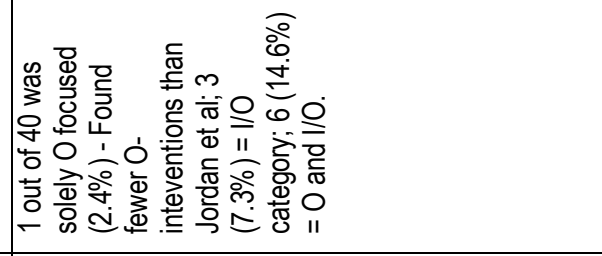 & 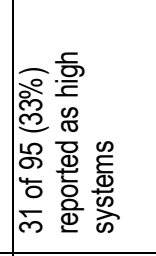 \\
\hline 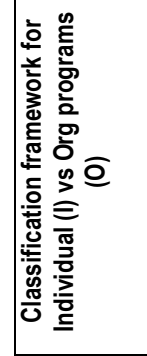 & 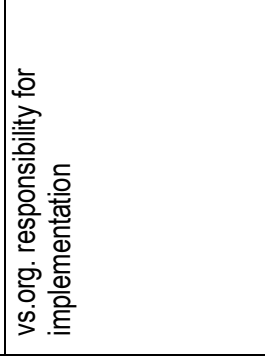 & 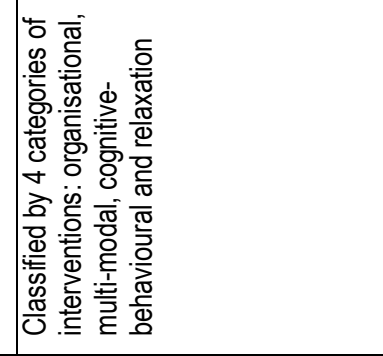 & 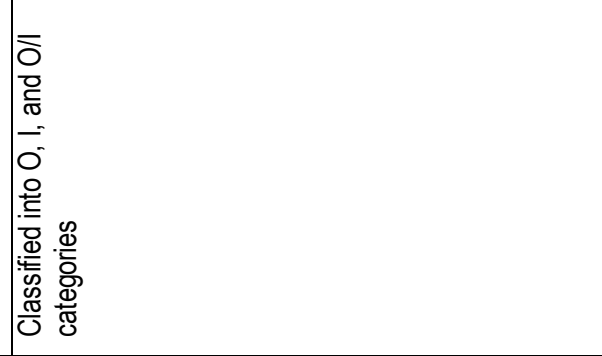 & 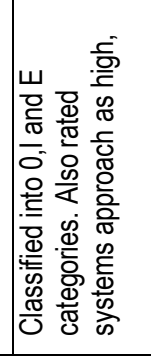 \\
\hline 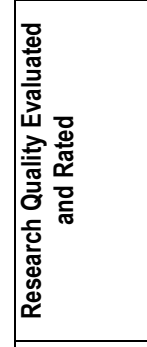 & 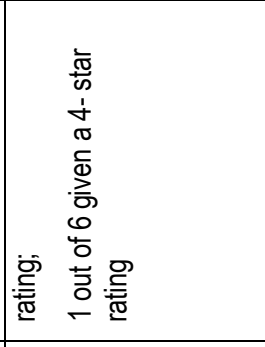 & 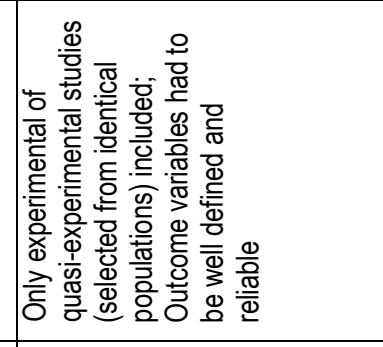 & 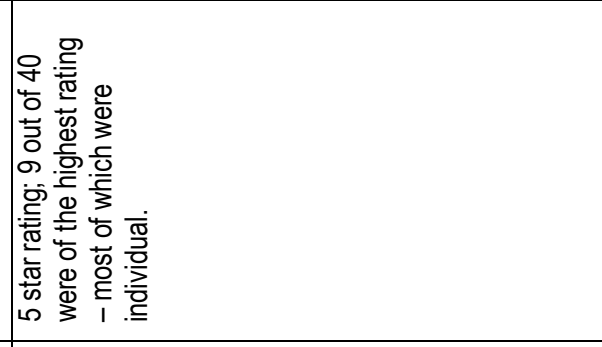 & 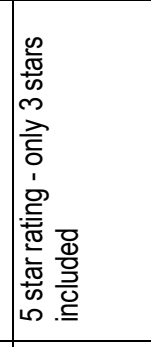 \\
\hline $\begin{array}{l}\frac{1}{0} \\
\frac{0}{0} \\
\frac{0}{4} \\
\end{array}$ & 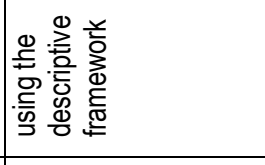 & 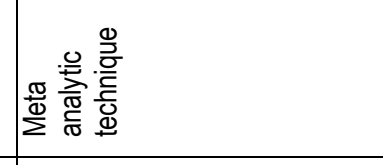 & 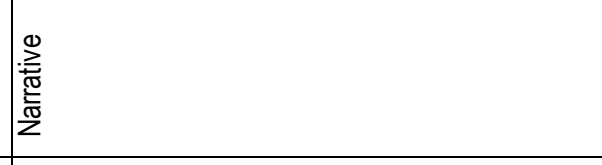 & 惫 \\
\hline 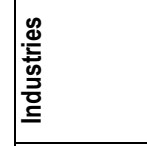 & 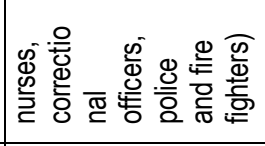 & 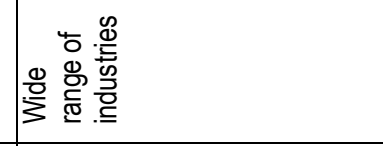 & 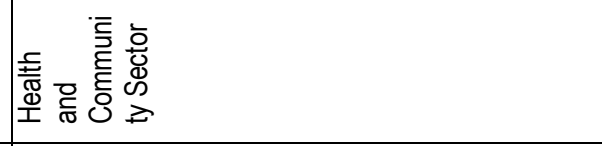 & 造 \\
\hline 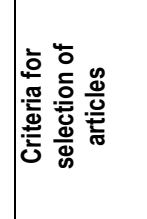 & 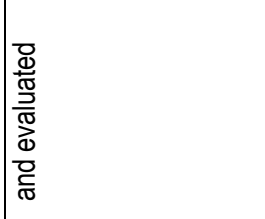 & 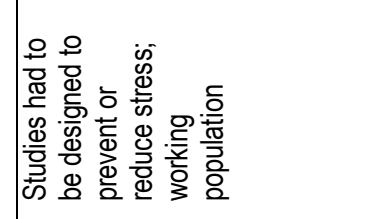 & 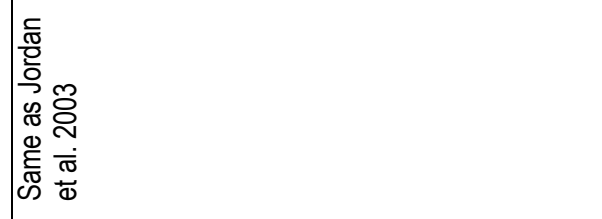 & 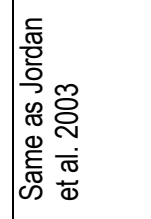 \\
\hline 总 & & 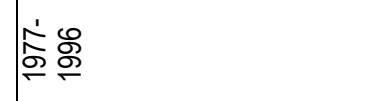 & ১্ণুণ্ণ & \\
\hline 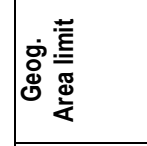 & & 프 & 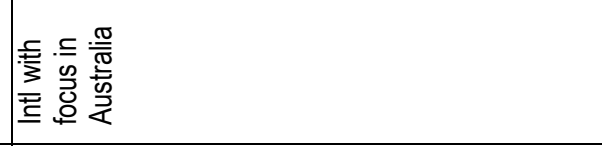 & $\underline{\underline{\underline{E}}}$ \\
\hline 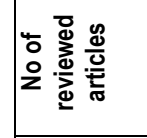 & & $\stackrel{\infty}{0}$ & 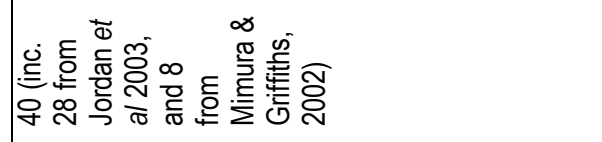 & 8 \\
\hline $\begin{array}{l}\frac{n}{0} \\
\frac{0}{2} \\
\frac{z}{4}\end{array}$ & & 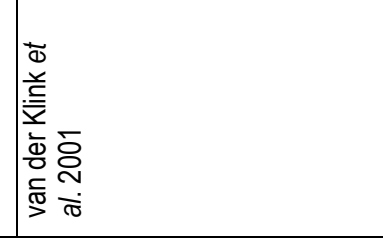 & 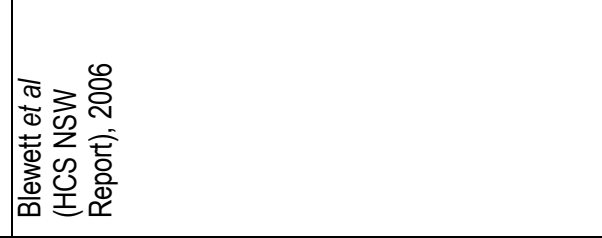 & 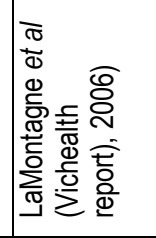 \\
\hline
\end{tabular}




\begin{tabular}{|c|c|c|}
\hline 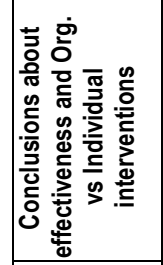 & 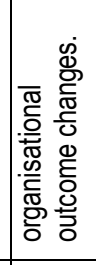 & 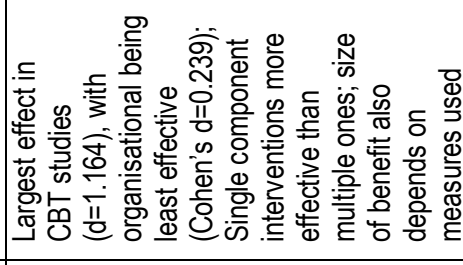 \\
\hline 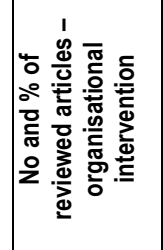 & \begin{tabular}{|l}
$\dot{\infty}$ \\
$\frac{0}{c}$ \\
$\frac{0}{0}$ \\
$\frac{0}{0}$ \\
$\frac{0}{\sigma}$ \\
$\frac{0}{\sigma}$
\end{tabular} & 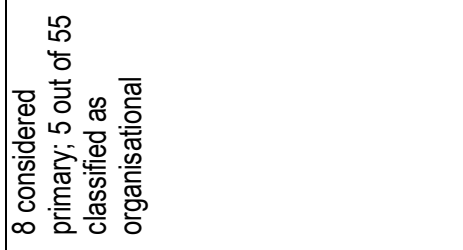 \\
\hline 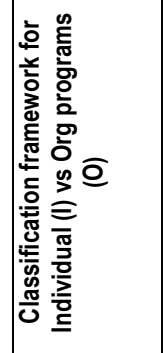 & 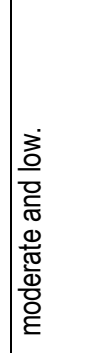 & 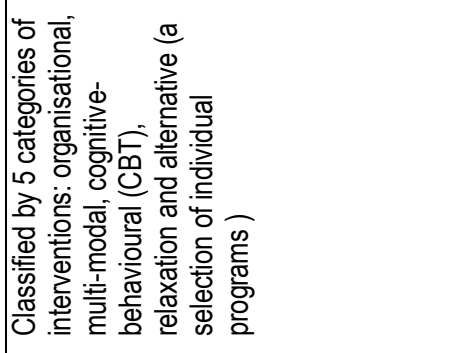 \\
\hline 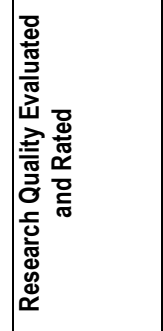 & & 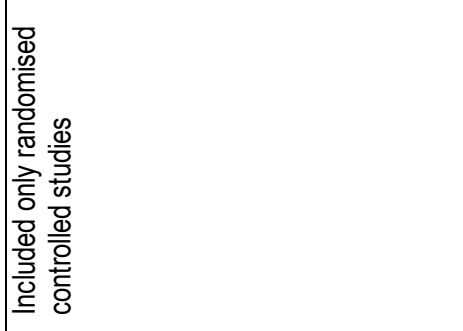 \\
\hline 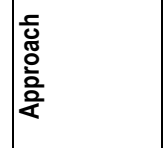 & & 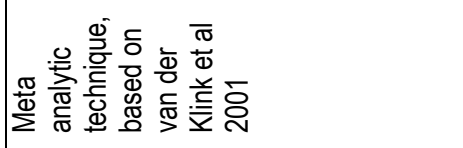 \\
\hline 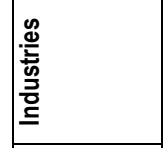 & & 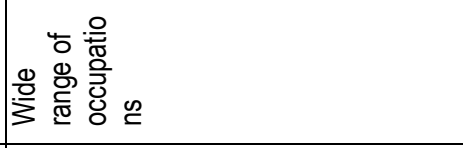 \\
\hline 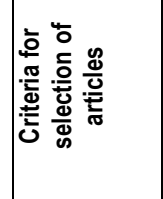 & & 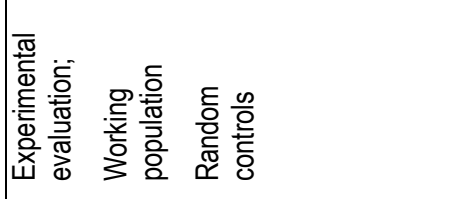 \\
\hline 产 & & 衣各 \\
\hline 竞 & & 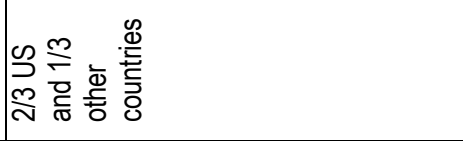 \\
\hline 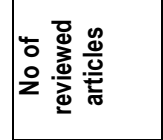 & & 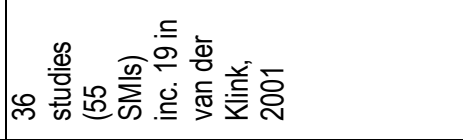 \\
\hline 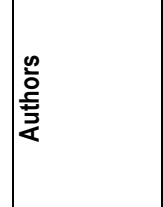 & & 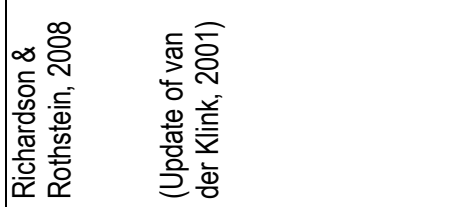 \\
\hline
\end{tabular}


As summarized in the table above, the organisational level interventions have been reported far less frequently than individual interventions. At most, the organisational approaches represent about $30 \%$ of evaluation studies.

There is some evidence from the reviews that individual approaches are effective to varying degrees in reducing the level of experienced stress. Studies focusing on individual level interventions tend to evaluate their effects within a short time frame, typically up to three months, following the intervention and measure the outcomes as reported by individuals. Subject to these limitations, it is known that CBT-based preventive approaches to training have produced a moderate positive effect for the individuals' stress outcomes (van der Klink et al. 2001). Many other studies reporting individual interventions have also found reduced stress effects for individuals but, most of these types of interventions do not utilise organisational measures and hence do not report effects at the organisational level (Richardson \& Rothstein 2008).

Systemic approaches, integrating both individual and organisational levels and all three categories, primary, secondary and tertiary, however, as reported in most recent studies, have proven to be the most effective (LaMontagne et al. 2006). Out of the source studies classified as "high systems" and using organisational evaluation measures $93 \%$ reported favourable results. This finding indicates that prevention of occupational stress is achievable when hazards are systemically identified and controlled within the workplace.

Few studies employed organisational level measures. In an example of such a study, the researchers found that improving working conditions through job redesign, monitoring psychological disorders and risk factors, and improving psychological health services resulted in positive outcomes for correctional officers. These included a significant reduction in the number of work stress claims, reduction in expenditures on the worker's compensation budget, and increased utilisation of the staff counsellor (Dollard, Forgan \& Winefield 2002).

This is consistent with other reviews most of which acknowledge the need to address both the organisational causes of work stress and their effects on individuals to gain most positive outcomes (Giga et al. 2003a).

\section{Bridging the gap between research and practice}

\section{Low frequency of systemic prevention}

There is a clear agreement amongst these researchers about the paucity of organisational and systemic interventions reported in the literature, in comparison with the individual approaches.

The findings of the analysis presented in Table 2, above have shown that out of 300 sources studies only some $60(20 \%)$ have had an organisational or primary focus. The most comprehensive meta-study in Australia conducted by Vichealth found almost $30 \%$ of the source studies were classified as "high systems" (LaMontagne et al. 2006). Very few studies reported systemic approaches aimed at addressing the sources of stress within the risk management framework. A British "Beacons of Excellence" HSE Study (Jordan et al. 2003) reported only 9 out 74 studies (12\%) fulfilled highly systemic criteria. The most recent meta analysis (Richardson \& Rothstein 2008) reported 9 primary intervention studies out of 36 reported source articles (25\%).

This analysis indicates that organisational, systemic approaches to stress intervention are adopted at a frequency of between $10-30 \%$ of all interventions, on the basis of the evaluations conducted with high validity methodologies.

\section{Management beliefs about stress and responsibility}

As the majority of stress interventions are focused on managing the individual's responses to their environment (Caulfield et al. 2004) within organisations, it can be concluded that the 
responsibility for its management, and therefore primary causation for this response, are vested in the individual worker.

This predominant approach to dealing with stress in organisations, in practice, appears to be in conflict with the mounting body of research pointing to certain aspects of work having clear links to the individual stress responses. This overwhelming preference for managing stress at the individual worker level is also in contrast with the evidence that organisationlevel interventions are superior (Cooper 2001).

The underlying reasons for this incongruence, it is proposed, can be found in the beliefs about stress amongst the decision makers. While the majority of managers believe workplace stress has adverse impact on employees and their performance at work, they do not favour organisational responses to managing stress. Managers tend to hold an individualised concept of stress and emphasize internal factors or individual failings and the individual approach to its management (Barley \& Knight 1992; Sharpley \& Gardner 2001; Dewe \& O’Driscoll 2002).

In the United States, researchers report that there remains a prevalent belief amongst employers that stress is personal, rather than a work-related problem which leads to their focus on individual stress management programs. Such programs also tap into the popular belief that stress is idiosyncratic and can be a positive for one person and a negative for another (Murphy \& Sauter 2003).

A recent Vichealth study involving in-depth interviews with 41 people in 29 organisations confirmed that stress was primarily seen as an individual issue, with most participants defining stress in terms of how it affected individuals. Organisational factors were mentioned only when participants were questioned further, mostly relying on their own experiences of stress (LaMontagne et al. 2006).

By way of contrast, Kinman and Jones (2005) found the predominant view was that perceived causes of workplace stress were of organisational nature and yet coupled with the belief that it was the individual's responsibility to deal with it. Their research points to the discrepancy between the known and perceived effectiveness of organisational strategies and the reality of the workplace favouring individual stress management approaches.

One reason for this gap between research and practice could be the lack of effective exchange of knowledge between the academic sphere and the real world of business. During the last 30 years that saw over 7800 refereed articles related to "occupational stress" published in research journals (as reported above), but there were only 320 published in the business related journals using the same key words (searched through EBSCOhost including the Business Source and Blackwell Encyclopedia of Business Library Complete).

It appears that the mounting evidence that work environment can have harmful effects on the employees' psychological health, has been by and large ignored by those in control of workplaces, despite their ethical and, in most developed countries, legal duty of care for creating risk-free workplaces for their workforce.

\section{Call for systemic action on stress prevention}

It seems that before systems interventions are more widely accepted in the workplace there is a need to align the decision makers' beliefs about stress, its causes and the responsibility for its management with the current research evidence. It is suggested that this can be achieved through two approaches: educational and evaluative. Greater awareness and education of managers about stress, particularly focusing on the roles of organisational personal versus organisational factors on stress processes will lead to changes of their beliefs and behaviour. More cases of systems approaches to stress intervention need to published and evaluated using organisational variables through well designed research studies. 
The currently required shift in the managers' thinking is analogous to that achieved in the traditional field of Occupational Health and Safety (OHS) and road safety during the last 25 years or so, at least in Australia.

The OHS has become accepted as an integral part of the modern workplace. The responsibility for providing a risk-free environment is taken seriously by employers. Appropriate budgets are allocated, staff are trained, systems created and implemented. As hazards are routinely identified, risks assessed, some risk controls include redesigning the systems of work to eliminate or reduce the risk of harm. There are punitive sanctions for any departure from the OHS laws and regulations. And yet, some time ago, different views and beliefs were held and it was the individuals who were responsible in the main for their own safety. Although some employers may still hold the view that OHS laws have gone too far in holding them responsible for their employees' safety behaviours, the social and economic benefit has been incalculable. Reporting on health and safety performance as part of corporate governance has become accepted as a norm for most organisations. What is missing from these reports, however, are the data on prevention of psychological ill-health.

To take another area of change in decision makers' beliefs and attitudes, it is also useful to consider the approach taken to prevention of motor vehicle accidents and improving road safety in the State of Victoria. The results of this approach have been publicly and easily measured by the road toll which stood at over 1000 in 1970 and gradually reduced to under 300 in 2009, while at the same time, the number of vehicle kilometres travelled increased dramatically.

If the beliefs that the individual drivers were solely responsible for their safety on the roads prevailed, it is unlikely that these reductions would have been achieved. To some extent it is still true that the individual's own behaviour and personality factors impact on the probability of their involvement in a motor vehicle accident. However, the focus of policy makers in the last few decades has been on improvements to all the components of the road user system: from mandating car safety features, road engineering, driver education, increasing penalties, to name a few.

Each of these changes was comprehensively evaluated and further adjustments made to the approach as more evidence became available. This is an example of a systems approach to a societal health and economic problem as a result of the new conceptualisation of the problem as an interaction between the individual and the environment. If the costs of workplace stress are to reduce, there needs to be a similar paradigm shift in beliefs amongst all of the significant stakeholders, and in particular, amongst organisational decision makers and those responsible for their corporate governance.

\section{Discussion and Conclusions}

Work stress is a costly phenomenon that has been increasingly recognised as a serious organisational and health issue internationally. There is a growing body of research evidence that some aspects of the work environment are hazardous to employee's health through a stress response that can lead to long-term poor health outcomes.

The evidence for the causal relationships between stress and poor health outcomes is overwhelmingly convincing and has been gathered over decades of research through workbased observations, and studies of biological pathways and epidemiological evidence.

There is a converging agreement on the definition of work stress as well as its theoretical process after many years of confusing and multiple definitions and frameworks. The consensus regarding its negative effects on individuals extends to organisations. However, there is a widening divergence between the known research and managers' beliefs about the causes of stress. While research points increasingly to organisational factors, the predominant belief in organisations is that it is a personal and individual issue. 
The assumption that the worker is responsible for dealing with stress stems from these beliefs and the lack of acceptance of work factors as a causation of stress. While the organisations recognise the negative effects of work stress they predominantly respond to it by implementing stress intervention programs that are individually rather than organisationally and preventively focused.

Although there are few studies of organisational interventions with robust research designs, there are clear indicators that systemic and comprehensive prevention programs have a significant and positive effect on the individual and organisational health.

Issues need to be addressed concerning the organisational responsibility for preventing and managing stress within the ethical framework of corporate responsibility for providing a riskfree environment for employees. The approach by governments to treat the issue of work stress as a health and safety aspect of organisational life has emphasized the Board's moral and legal obligation to ensure it is managed at the organisational level.

The evidence clearly points to the need for more systemic and preventive approaches to managing stress in the workplace as these can be more valuable for both organisations and their employees. There is also a potential for organisations to benefit significantly from a healthier work environment created by focusing on those aspects of work that reduce employee distress and increase wellbeing within a specific context.

\section{References}

Australian Safety and Compensation Council (2008) Compendium of workers' compensation statistics: Australia 2004-05, Canberra, Australia.

Australian Safety and Compensation Council (2009) The cost of work-related injury and illness for Australian Employers, Workers and the Community: 2005-06, Canberra, Australia.

Barley S R \& Knight D B (1992) Toward a Cultural Theory of Stress Complaints. Research in Organisational Behaviour, 14, 1/48.

Blewett V, Shaw A, LaMontagne A, \& Dollard M (2006) Job Stress: Causes, Impact and Interventions in the Health, and Community Services Sector. WorkCover New South Wales, November.

Biron C, Ivers H, Brun J \& Cooper C (2006) Risk assessment of occupational stress: Extensions of the Clarke and Cooper approach. Health, Risk \& Society 8 (4) 417-429.

Bosma H, Marmot M G, Hemingway H, Nicholson AG, Brunner E \& Stansfeld A (1997) Low job control and risk of coronary heart disease in Whitehall II (prospective cohort) study. BMJ, Vol. 314:558-65.

Briner R B (1996) Stress talk: sociocultural approaches to understanding organisational stress. Proceedings of the BPS Occupational Psychology Conference: January, Eastbourne, UK.

Cooper C L (2001) Theories of Organizational Stress, Oxford University Press, USA.

Cooper C L, Dewe P J, \& O'Driscoll M P (2001) Organizational Stress. A Review and Critique of Theory, Research, and Applications, London: Sage Publications.

Caulfield N, Chang D, Dollard M F \& Elshaug C (2004) A Review of Occupational Stress Interventions in Australia., International Journal of Stress Management, 11(2), 149-166.

Cotton P \& Hart P M (2003) Occupational Wellbeing and Performance: A Review of Organisational Health Research. Australian Psychologist 38(2): 118.

Cox T \& Griffiths A (1995) The nature and measurement of work stress: theory and practice. In J. Wilson \& N. Corlett (eds.). The Evaluation of Human Work: A Practical Ergnonomics Methodology, London: Taylor and Francis.

Cox T, Griffiths A, Barlowe C, Randall R, Thomson L \& Rial-Gonzalez E (2000) Organisational interventions for work stress. A risk management approach. Institute of Work, Health and Organisations. University of Nottingham Business School. HSE Report 286/2000. 
Cox T \& Mackay C J (1981) A transactional approach to occupational stress. In: Corlett E N \& Richardson J (eds). Stress, Work Design and Productivity, 10-34.. Wiley \& Sons, Chichester,

De Bruin G. F \& Taylor N (2005) Development of the sources of work stress inventory. South African Journal Psychology 35: 748-765.

D'Aleo N P, Stebbins P, Lowe R, Lees D \& Ham D (2007) Managing Workplace Stress Psychosocial Hazard Risk Profiles in Public and Private Sector Australia Australian Journal of Rehabilitation Counselling 13(2): 68-87.

Dewe P \& O'Driscoll M (2002) Stress management interventions: what do managers actually do? Personnel Review, 31, 143/ 165.

Dollard M F, Forgan R \& Winefield H R (2002) Five-year evaluation of a work stress intervention program. Journal of Occupational Health and Safety 14: 159-165.

Dollard M F, Winefield A H, \& Winefield H R (Eds) (2003) Occupational Stress in the Service Professions. Taylor and Francis: London.

Dollard M F \& Knott V (2004) Incorporating psychosocial issues into our conceptual models of OHS. Journal of Occupational Health and Safety, Australia and New Zealand 20: 345-358.

European Agency for Safety \& Health (2007) Expert forecast on emerging psychosocial risks to occupational safety and health, Belgium.

Giga S I, Cooper C L \& Faragher B (2003a) The Development of a Framework for a Comprehensive Approach to Stress Management Interventions at Work. International Journal of Stress Management, Vol 10(4), Nov, 280-296.

Giga S I, Noblet A J, Faragher B \& Cooper C L (2003b) The UK Perspective: A Review of Research on Organisational Stress Management Interventions. Australian Psychologist 38(1): 158-164.

Israel B A, Baker E A, Goldenhar L M \& Heaney C A (1996). Occupational stress, safety, and health: Conceptual framework and principles for effective prevention interventions." Journal of Occupational Health Psychology 1(3): 261-286.

Ivancevich J M, Matteson M T, Freedman S M \& Phillips J S (1990). Worksite stress management interventions, American Psychologist 45(2): 252-261.

Jex S, Beehr T \& Roberts C (1992) The meaning of occupational stress items to survey respondents. Journal of Applied Psychology 77: 623-628.

Jordan J E, Gurr E, Tinline G, Giga S, Faragher B \& Cooper C (2003) Beacons of excellence in stress prevention. HSE Research Report R133.

Karasek R A (1979) Job demands, job decision latitude, and mental strain: Implication for job redesign. Administrative Science Quarterly, 24, 285-308, 1979

Karasek R \& Theorell T (1990) Healthy work: Stress, productivity and the reconstruction of working life. New York: Basic Books.

Kinman, G. \& Jones F, (2005). Lay representations of workplace stress: What do people really mean when they say they are stressed? Work \& Stress 19(2): 101-120.

Kompier M A J, Cooper C L \& Geurts S A E. (2000) A multiple case study approach to work stress prevention in Europe. European Journal of Work \& Organizational Psychology 9(3): 371-400.

LaMontagne A D, Louie A, Keegel T, Ostry A \& Shaw A (2006) Workplace stress in Victoria: Developing a systems approach. Report to the Victorian Health Promotion Foundation.

Mackay C J, Cousins R, Kelly P J, Lee S \& McCaig R H (2004) Management Standards” and work-related stress in the UK: Policy background and science. Work \& Stress, AprilJune, Vol 18 (2), 91-112.

Mimura C \& Griffiths P (2003). The effectiveness of current approaches to workplace stress management in the nursing profession: an evidence based literature review. Occupational And Environmental Medicine 60(1): 10-15.

Murphy L R \& Sauter S L (2003) The USA Perspective: Current Issues and Trends in the Management of Work Stress. Australian Psychologist 38(2): 151-157. 
Newman J E, \& Beehr T A (1979) Personal and organizational strategies for handling job stress: A review of research and opinion. Personnel Psychology, 32, 1-43

Redfern D C, Rees C J \& Rowlands K E (2008) Occupational stress: consensus or divergence? A challenge for training and development specialists. Industrial \& Commercial Training. 40(6): 287-294.

Richardson K M \& Rothstein H R (2008) Effects of Occupational Stress Management Intervention Programs: A Meta-Analysis. Journal of Occupational Health Psychology 13(1): 69-93.

Rolls Royce Annual Report (2006), viewed 31 August 2010, < $\underline{\text { http://www.rolls- }}$ royce.com/reports/2006/index.shtml>

Rolls Royce Global Code of Business Ethics (2009), viewed 31 August 2010, $<$ http://www.rolls-royce.com/Images/ethicscode_eng tcm92-13314.pdf $>$

Sanders M A (2001) Minimizing stress in the workplace: Whose responsibility is it? Work 17(3): 263.

Senol-Durak E, Durak M \& Gençöz T (2006) Development of work stress scale for correctional officers. Journal of Occupational Rehabilitation 16: 157-168.

Selye H (1956) The Stress of life, USA: McGraw-Hill.

Selye H (1974) Stress without distress, Philadelphia: J.B. Lipincott.

Sharpley C \& Gardner J (2001) Managers understanding of stress and its effects in the workplace. Journal of Applied Health Behaviour, 3, 24/30.

Sutherland V J \& Cooper C L (2000) Strategic Stress Management. Palgrave, New York

van der Hek H. \& Plomp H N, (1997). Occupational stress management programmes: a practical overview of published effect studies. Occupational Medicine (Oxford, England) 47(3): 133-141.

van der Klink J J L, Blonk R W B, Schene A H \& van Dijk F J (2001). The Benefits of Interventions for Work-Related Stress. American Journal of Public Health 91(2): 270276.

Yusuf S, Hawken S \& Ounpuu S (2004) Effect of potentially modifiable risk factors associated with myocardial infarction in 52 countries (the INTERHEART study): casecontrol study. Lancet: 364:937-952. 